Manuscript ID ZUMJ-1911-1613 (R2)

DOI

10.21608/zumj.2020.19016.1613

ORIGINAL ARTICLE

\title{
The Efficacy of Intralesional Steroid Injection in the Treatment Of Corrosive Esophageal Strictures in Children
}

\author{
Saad El-Sayed Ahmed Mansour ${ }^{(1)}$, Hatem Mohamed El-Sayed Hussin ${ }^{(1)}$, Nadia El-Shahat Ismail \\ Soliman ${ }^{(1) *}$
}

1: Pediatric deparment, faculity of medicine, zagazig university

*Correspoding author:

Nadia El-Shahat Ismail

Soliman

Pediatric resident at shoprahour hospital, faculity

of medicine ,AL Azhar

university

Nadia_elshahat@yahoo.com

$\begin{array}{ll}\text { Submit Date } & \text { 2020-01-17 } \\ \text { Revise Date } & \text { 2020-04-12 } \\ \text { Accept Date } & \text { 2020-04-22 }\end{array}$

\begin{abstract}
Background: In the treatment of serious corrosive esophageal strictures, esophageal dilatation may be inadequate. The purpose of this study was to evaluate the effectiveness of intralesional steroid injection as an adjunct to dilatation therapy. Methods: This is a clinical trial study, which was conducted on 42 patients with corrosive esophageal stricture. The patients were admitted to pediatric endoscopic department at Zagazig University Hospitals. They were randomly divided into 2 groups. Group 1/Controls: 21 patients (10 males and 11 females; mean age $28 \pm 20.8$ months), who received dilatation therapy only. Group 2/Cases: 21 patients (13 males and 8 females; mean age 40.4 20.5 months), who received an additional treatment by $1 \mathrm{ml}$ intralesional steroid injection of triamcinolone actenoid in the strict part. Results: Number of dilatation therapy, dysphagia and vomiting were highly statistically significantly decreased in study group vs control group. At the end of the follow-up period, $30 \%$ of control group improved while $85 \%$ of the study group improved. Conclusions: The findings of the current study support the use of intralesional triamcinolone in corrosive esoghageal stricture as an adjuvant treatment to dilatation therapy, as it improved the outcome in the studied cases.
\end{abstract}

Key Words: Intralesional steroid injection, Corrosive esophageal stricture, Caustics, esophageal dilatation, triamcinolone.

\section{INTRODUCTION}

Corrosive esophageal strictures (CES) are important public health problem in developing countries as it considered one of the most frequent forms of esophgaitis in children. It is extended more in the rural community than others, as the super-vision of small children is decreased [1].

The severity of the esophageal stricture is dependent on two important factors; the type and concentration of caustic agent which may be acid or alkali. The severe lesions are caused by acids with a $\mathrm{pH}$ less than 3 or by bases with a $\mathrm{pH}$ greater than 11 [2].
In children with corrosive esophageal stenosis, dysphagia is a frequent symptom and significantly affects the life's quality [3]. There are several endoscopic techniques could be used as esophageal stent, balloon dilatations or Savary- Gilliard dilators, Hurst dilators, etc., but in fact, there is no universal standardization for these techniques in patients' management so other lines of treatment as topical mitomycin, or steroid injection can be used as an adjunct to dilatation therapy [4].

Intralesional steroid injection is preferred to augment the effect of dilatation by preventing collagen formation at the stricture part, using 
triamcinolone acetonide, which is a synthetic corticosteroid with preventive effect on collagen synthesis, fibrosis and chronic healing. It has been used for several years, to promote healing and reduce the needed number of dilatations [5]. The current study was conducted to evaluate the effectiveness of intralesional steroid injection as an adjunct to dilatation therapy.

\section{METHODS}

This is a clinical trial study, which was conducted on 42 patients with corrosive esophageal stricture. The patients were admitted to pediatric endoscopic department at Zagazig University Hospitals during the period from February 2017 to September 2018. They were randomly divided into 2 groups. Group 1/Controls: 21 patients (10 males and 11 females; mean age $28 \pm 20.8$ months), who received dilatation therapy only. Group 2/Cases: 21 patients (13 males and 8 females; mean age $40.4 \pm 20.5$ months), who received an additional treatment by $1 \mathrm{ml}$ intralesional steroid injection of triamcinolone actenoid in the strict part.

Ethical Clearance: Written informed consent for participation in the study was obtained from the patients' parents. Approval was received from the Pediatrics Department, Zagazig University Hospitals for conducting the study after the approval of the Institutional Review Board (IRB). The work was carried out for human studies in accordance with the World Medical Association's Code of Ethics (Decleration of Helsinki).

Inclusion criteria: Any child with corrosive esophageal stricture and received on dilatation therapy, aged from 9months to 84 months (7years), was included in this study. The duration of stricture and number of previous dilatation session were included and mentioned in the part of history taking. Exclusion criteria: Children on regular steroid therapy for different reasons, who had esophageal strictures due to reasons other than corrosive ingestion (such as congenital atresia, peptic ulcer disease, as a complication of gastroesophageal reflux, after surgical repair of esophageal atresia and during chemotherapy) and whom parents refuse enrollment into the study were excluded from the study.

All participants in the study had been subjected to complete history taking regarding name, age, history of corrosive substance ingestion, type and amount of ingested substance, examination of the oral cavity which may reveal hyperemia, edema or ulcerations, weight measurement, height measurement: and the following investigations: Barium esophagogram (for diagnosis), complete blood count, bleeding profile and plain chest xray after dilatation (to detect perforation) were done.

\section{Description of the technique:}

In the control group, the endoscopic dilatation procedure was done under general anesthesia, and a specialized pediatric anesthesiologist administered the used medications for anesthesia. Savary-Gilliard dilators were used. first passing a flexible metallic guidewire through the stricture until reaching the stricture and then passing a different caliber Savary dilators $(7 \mathrm{~mm}, 9 \mathrm{~mm}, 11$ $\mathrm{mm}, 12.8 \mathrm{~mm}$ ) depending on the stricting diameter. Most subsequent dilatation procedures were scheduled in 2 weeks until achievement of intraluminal dilatation of the esophagus (12.8mm), improvement of patient's symptoms, or earlier if patients returned with further dysphagia.

In the study group, the dilatation therapy had been combined with intralesional steroid injection in the form of triamcinolone acetonide (named Epirelefan $40 \mathrm{mg} / 1 \mathrm{~mL}$, concenterated solution) injections.

Intralesional triamcinolone acetonide application:

Esophageal dilatation under general anesthesia with a Pentax $8.7 \mathrm{~mm}$ flexible endoscope was introduced and a sclerotherapy needle $2.3 \mathrm{~mm}$ in diameter and $180 \mathrm{~cm}$ long was passed through the opera-ting channel to apply the triamcinolone acetonide intralesionally at a concentration of 40 $\mathrm{mg} / \mathrm{ml}$. Firstly the needle was filled with steroid about $0.75 \mathrm{ml}$ after that under direct vision, then $0.25 \mathrm{ml}$ applied per quadrant in the proximal part of constricted area, injected in four quadrants and it was given every 2 weeks for 2 months or until 
improvement of patient's clinical picture. Injections were given just before dilatation.

Patients with specific attention to chest pain, abdominal pain, and difficulties in breathing and hemodynamic status were observed for 4 hours after each dilatation. In the same day of the procedure, the patients were discharged with instructions to monitor the occurrence of fever, chest pain or breathlessness.

The patients were followed-up for 6 months and the outcome was assessed according to the number of dilatation therapy, the occurrence of dysphagia or vomiting and the weight gain, with comparing these parameters between the controls and the studied cases.

\section{Statistical Analysis}

All statistical analysis was conducted using IBM SPSS Statistics, version 24.0 (IBM; Armonk, New York, United States). Continuous variables were presented as the mean $\pm \mathrm{SD}$ if normally distributed or median(range) if not normally distributed. Normality was checked by ShapiroWilk test. Categorical variables were presented by the count and percentage. Chi-squared test is used to discover if there is a relationship between two categorical variables.

Mann-Whitney $\mathrm{u}$ test is used to compare differences between two independent groups when the dependent variable is either ordinal or continuous, but not normally distributed.

Kaplan-Meier survival plot is the most commonly used method to illustrate survival curve. It is used to estimate time-to-event for a group of individuals (e.g., time to improvement).

\section{RESULTS}

The controls aged from 9 months to 9-72 months and they were 11 females and 10 males, 14 patients with acid ingestion and 7 patients with alkaline ingestion. All of them presented with vomiting and their median(range) dysphagia score was 3(2-4). The mean number of dilatation therapy was $3 \pm 1.4$, the level of stricture in them is different and the mean length of strictures from central incisors is $6 \pm 2.0 \mathrm{~cm}$ as shown in tables $(1,2)$.

The cases aged from 18 months to 84 months and they were 8 females and 13 males, 14 patient with acid ingestion and 7 patient with alkaline ingestion .They presented with vomiting and their median dysphagia score was 3 (2-4). The mean number of dilatation therapy was $8 \pm 1.5$, the level of stricture in them is different and the mean length of strictures from central incisors is $7.4 \pm 2.6 \mathrm{~cm}$ as shown in tables $(1,2)$

Number of dilatation therapy was highly statistically significantly decreased in the cases vs the controls $(P<.001)$, as shown in figure (1). Dysphagia score was statistically significantly lower in cases group vs control group $(P=.029)$, as shown in figure (2). Percentage of patients with vomiting was statistically significantly lower in the cases group than the control group $(P=.014)$, as shown in figure (3) and percentage of patients with weight gain was statistically significantly higher in the cases group than control group $(P=.024)$, as shown in table (3), and figure (4).

Kaplan-Meier survival analysis indicated a significant difference in symptom-free survival between both groups over a six-month follow up period (log-rank, $P<.001$ ), as at the end of the follow up period, $30 \%$ of the control group improved (one patient of that group at $3^{\text {rd }}$ month underwent surgery) while $85 \%$ of the cases group improved, as shown in figure (5). 
Table 1. Predilation baseline clinical characteristics in esophageal strictures patients

\begin{tabular}{|c|c|c|}
\hline \multirow[t]{2}{*}{ Variables } & Control group & Study group \\
\hline & $\mathrm{n}=21$ & $\mathrm{n}=21$ \\
\hline \multicolumn{3}{|l|}{ Age (months) } \\
\hline Mean \pm SD & $28.1 \pm 20.8$ & $40.4 \pm 20.5$ \\
\hline Median (range) & $19(9-72)$ & $36(18-84)$ \\
\hline \multicolumn{3}{|l|}{$\operatorname{Sex}, \mathbf{n}(\%)$} \\
\hline Female & $11(52)$ & $8(38)$ \\
\hline Male & $10(48)$ & $13(62)$ \\
\hline \multicolumn{3}{|l|}{ Type of corrosive, $\mathbf{n}(\%)$} \\
\hline Acid & $14(67)$ & $14(67)$ \\
\hline Alkali & $7(33)$ & $7(33)$ \\
\hline \multicolumn{3}{|l|}{ Vomiting, n(\%) } \\
\hline Yes & $21(100)$ & $21(100)$ \\
\hline No & $0(0)$ & $0(0)$ \\
\hline \multicolumn{3}{|l|}{ *Dysphagia score } \\
\hline median(range) & $3(2-4)$ & $3(2-4)$ \\
\hline
\end{tabular}

*lower scores are better

Table 2. Baseline data of dilation of esophageal strictures patients

\begin{tabular}{|l|c|c|}
\hline Variables & Control group & Study group \\
\hline Number of dilation therapy & $\mathrm{n}=21$ & $\mathrm{n}=21$ \\
\hline Mean \pm SD & $3 \pm 1.4$ & $8 \pm 1.5$ \\
\hline Median (Range) & $3(1-5)$ & $8(6-10)$ \\
\hline Level of stricture(cm)from central incisor $\mathbf{n}(\boldsymbol{\%})$ & \\
\hline $10-15$ & $2(10)$ & $3(14)$ \\
\hline $10-20$ & $4(19)$ & $6(29)$ \\
\hline $15-20$ & $15(71)$ & $11(52)$ \\
\hline $15-25$ & $0(0)$ & $1(5)$ \\
\hline Length of stricture (cm) & & \\
\hline Mean \pm SD & $6 \pm 2.0$ & $7.4 \pm 2.6$ \\
\hline Median (Range) & $5(5-10)$ & $5(5-10)$ \\
\hline
\end{tabular}


Table 3. Clinical outcome of esophageal strictures patients

\begin{tabular}{|c|c|c|c|c|}
\hline \multirow[t]{2}{*}{ Variables } & Control group & Study group & \multirow[t]{2}{*}{ Significance test } & \multirow[t]{2}{*}{$P$-value } \\
\hline & $\mathrm{n}=21$ & $\mathrm{n}=21$ & & \\
\hline \multicolumn{3}{|c|}{ Number of dilation therapy } & \multirow{2}{*}{$\begin{array}{c}\text { Mann-Whitney } U \\
\text { test }=38.5\end{array}$} & \multirow[t]{2}{*}{$<.001$} \\
\hline Median (Range) & $5(1-7)$ & $1(1-3)$ & & \\
\hline \multicolumn{3}{|l|}{ *Dysphagia } & \multirow{2}{*}{$\begin{array}{c}\text { Mann-Whitney } U \\
\text { test }=136.5\end{array}$} & \multirow[t]{2}{*}{.029} \\
\hline Median (range) & $2(0-4)$ & $1(0-2)$ & & \\
\hline \multicolumn{3}{|l|}{ Vomiting, n(\%) } & \multirow[t]{3}{*}{$\chi^{2}=6.1$} & \multirow[t]{3}{*}{.014} \\
\hline Yes & $9(43)$ & $2(10)$ & & \\
\hline No & $12(57)$ & $19(91)$ & & \\
\hline \multicolumn{3}{|c|}{ Weight gain, n(\%) } & \multirow{3}{*}{$\chi^{2}=5.1$} & \multirow[t]{3}{*}{.024} \\
\hline Yes & $10(48)$ & $17(81)$ & & \\
\hline No & $11(52)$ & $4(19)$ & & \\
\hline
\end{tabular}

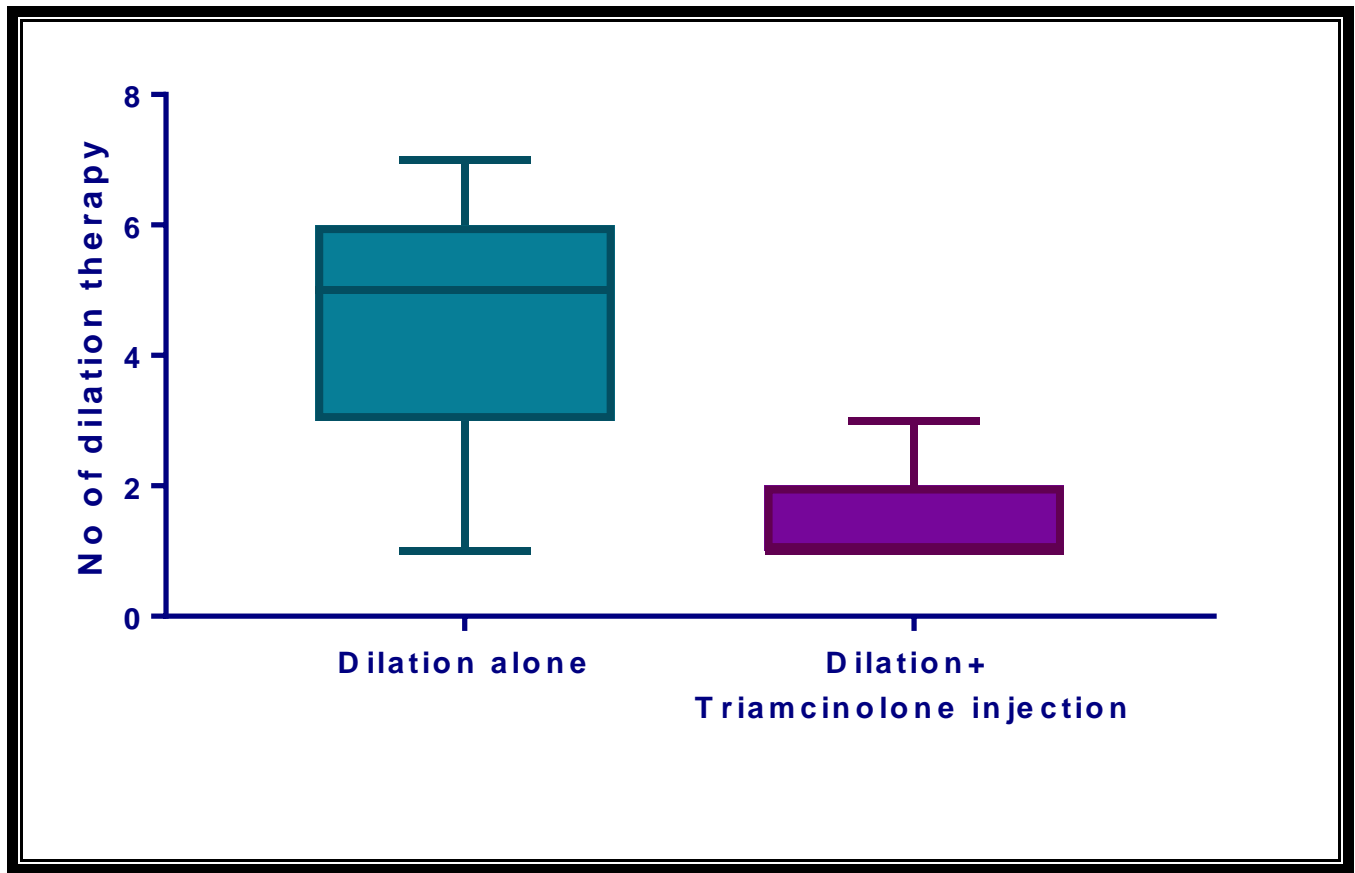

Figure 1. Boxplot showing number of dilation therapy in Dilation alone(the control group) vs Dilation+Triamcinolone injection(the study group) 


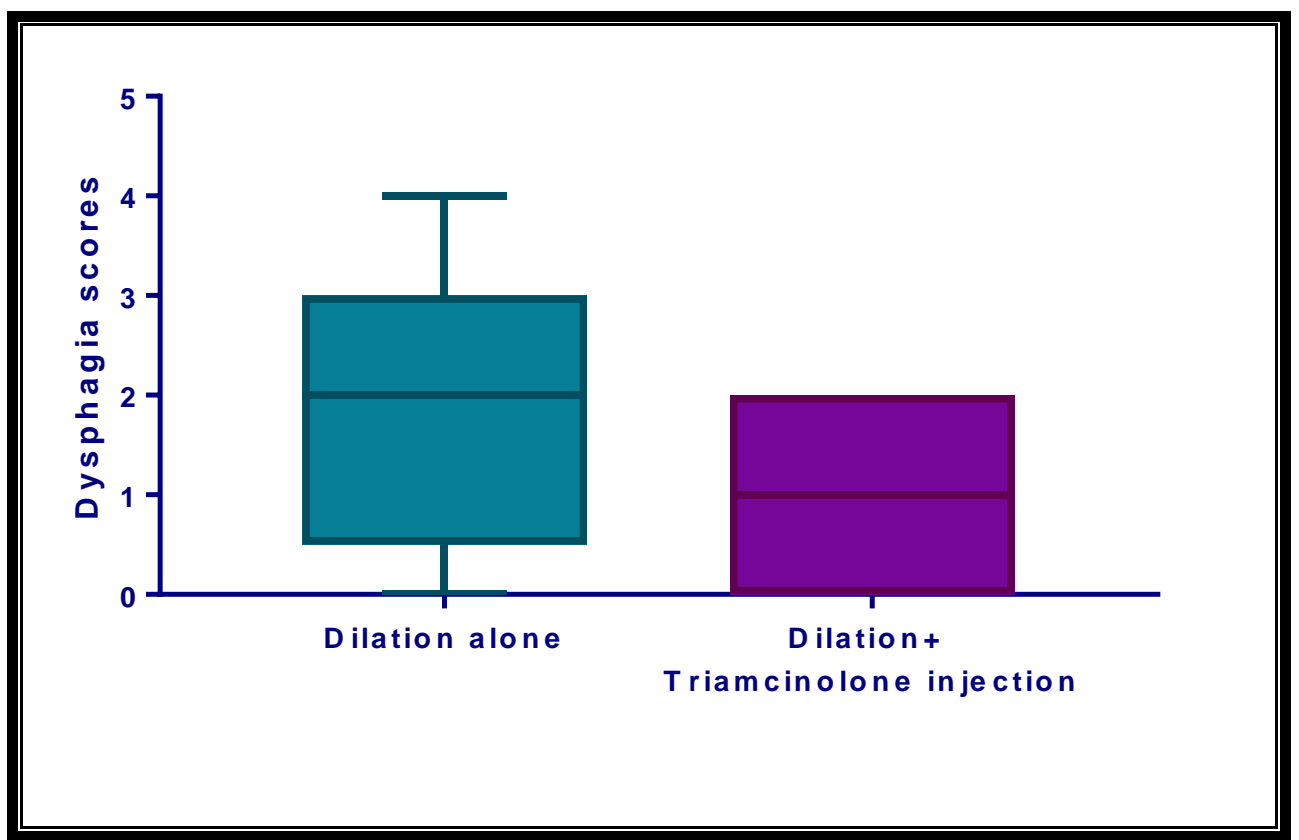

Figure 2. Boxplot showing dysphagia scores in Dilation alone group vs Dilation+Triamcinolone injection in esophageal strictures patients

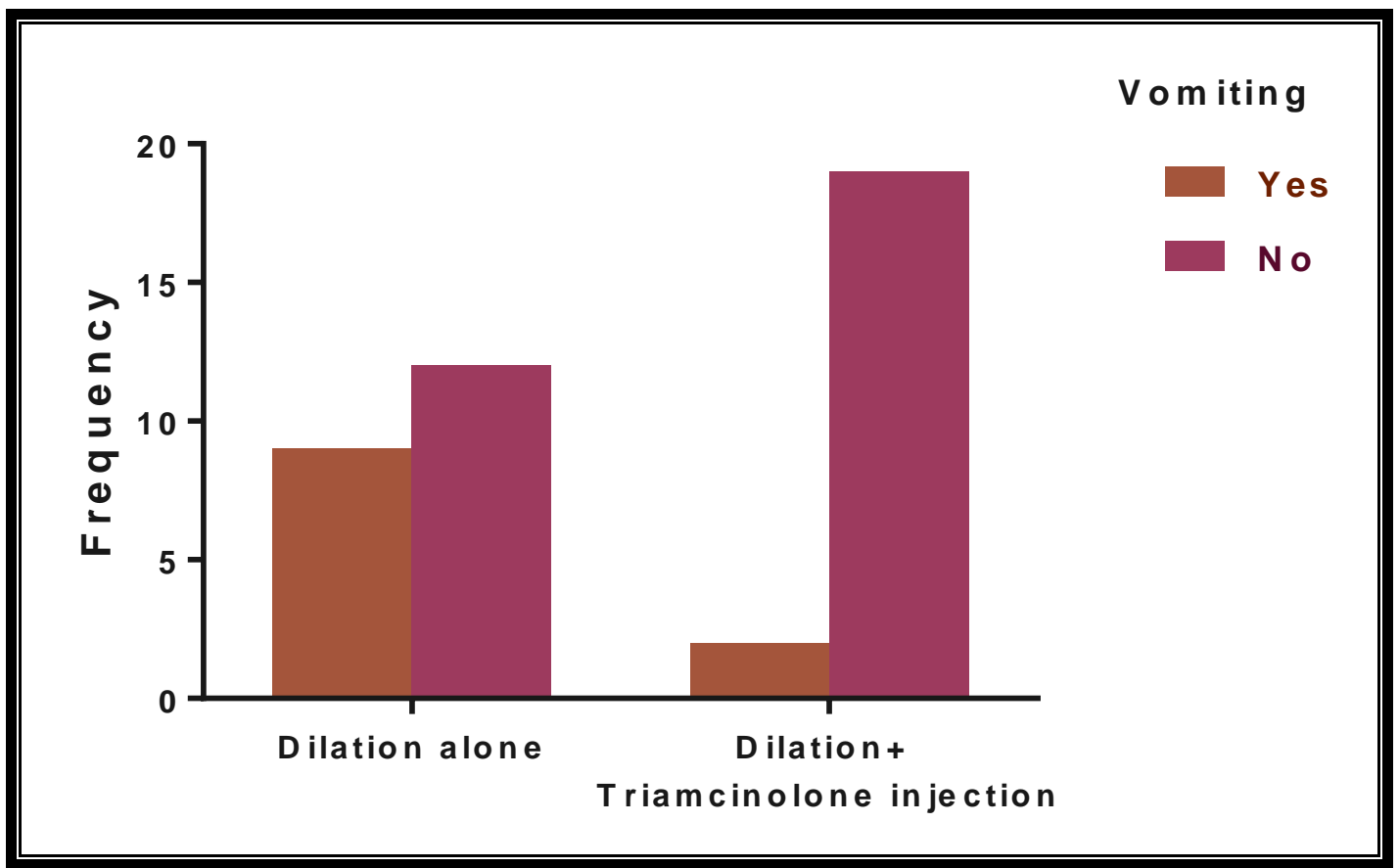

Figure 3. Bar chart showing frequency of vomiting distribution in Dilation alone group vs Dilation+ Triamcinolone injection in esophageal strictures patients 


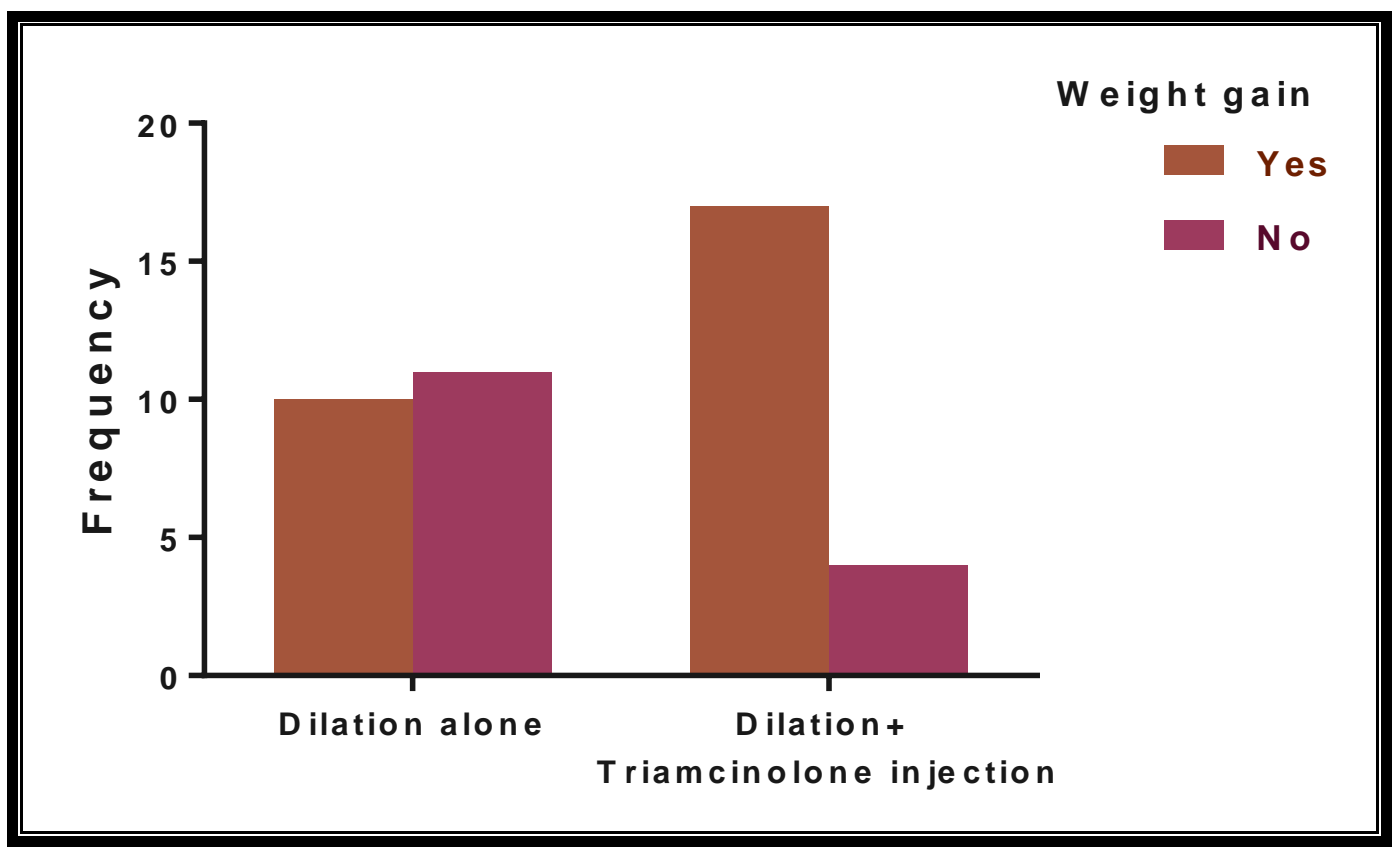

Figure 4. Bar chart showing frequency of weight gain distribution in Dilation alone group vs Dilation+ Triamcinolone injection in esophageal strictures patients.

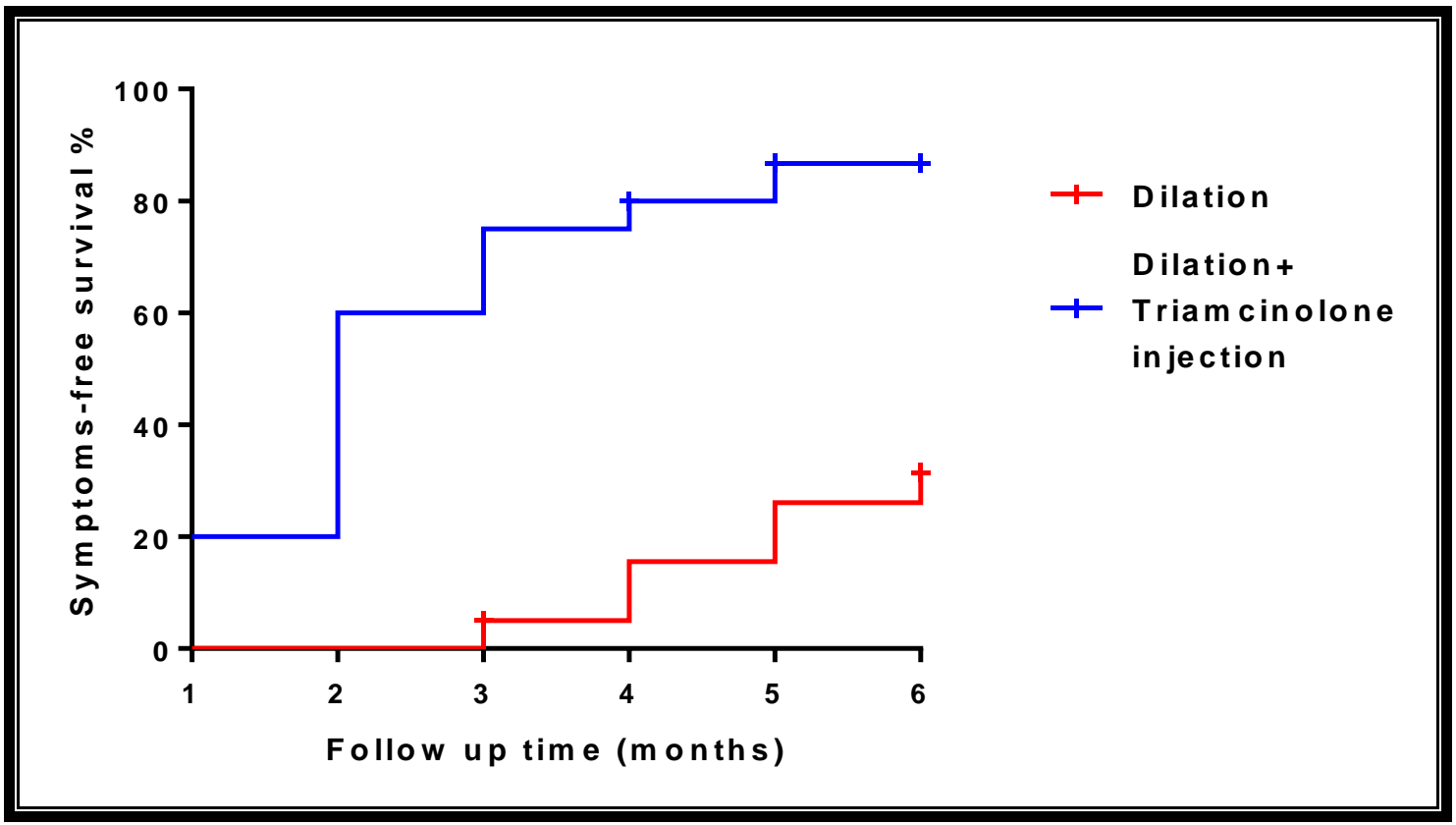

Figure 5. Kaplan-Meier survival plot showing time to improvement in control goup vs the study group during a six-month follow up period. At the end of the follow up period, $30 \%$ of Dilation group improved (one patient of that group at $3^{\text {rd }}$ month underwent surgery) while $85 \%$ of Dilation+Triamcinolone injection group improved 


\section{DISCUSSION}

Esophageal dilation is the primary treatment of esophageal stenosis due to caustic ingestion. In spite of an extensive dilation regimen and gastroesophageal reflux treatment, some patients with esophageal rigidities do not receive adequate symptom relief. In these cases, injection of corticosteroids at the site of the lesion can reduce the severity of recurrence after dilation.

In this study, intralesional injection of steroids decreased the number of dilatations. This finding coincides with the study of Takahashi et al., who reported that endoscopic triamcinolone injection reduced the mean number of dilatation sessions per patient from 12.5 to 6.1 [7].

Another study was done on 25 patients showed that intralesional steiod injection reduced the mean number of dilatations required over time [8].

Kochhar and Makharia, in their study used triamcinolone acetonide $(10 \mathrm{mg} / \mathrm{mL})$ in 17 patients with caustic-induced esophageal strictures, 14 of whom had regular dilations, while the other three had not yet been dilated. The mean number of dilations in these patients was 27.9 in a 22-month period before injections of steroids and 3.57 in a 10.5-month period after injections of steroids. Significantly, after the steroid injection, three patients did not require further dilation [9].

Altintas et al., reported that there was no significant difference between controls and the studied cases regarding the total number of dilatations in a clinical trial sample involving 21 patients [10].

In this study, a maximum of three sessions of steroid injection was conducted. The number of sessions is a non-settled issue that requires standardization. In the recorded amount, the number of injection sessions ranges from just one to as many sessions as the number of dilations. Several research used up to four sessions, up to five or 13 sessions [11]. Another study limited the total number of injections of steroids to three [5].
In the current study, there was no need for repeated dilations after steroid injection in 17 of 21 patients, a finding, which is consistent with Zein et al., who reported that four of seven patients with esophageal strictures required no more dilation after the injection of steroid [12].

According to the best of our knowledge, several parallel studies to our work were concerned with improvement of dysphagia, but there are no published studies regarding the improvement of vomiting and weight gain.

In a study done on nine patients with complex rigidities of different etiologies (2 postoperative, 3 gastroesophageal reflux disease, and 4 caustic) with intralesional triamcinolone injections followed by endoscopic dilations, dysphagia was improved [13].

In agreement with the findings this study, intralesional triamcinolone injections for patients who are refractory to repeated dilations for esophageal stricture after acid ingestion were effective in decreasing the mean dysphagia score from 2.64 to 0.81 and mean number of dilations needed before and after steroids injection, as well [14]., the same results were obtained by Kochhar and Makharia, who reported a decrease in dysphagia score from 2,34 to 0,656 [9].

In this study intralesional steroid injection was used as adjuvant treatment to dilatation therapy in children with corrosive esophageal stricture whatever the cause (acidic or alkaline).

In the treatment approach, $1 \mathrm{ml}(40 \mathrm{mg} / \mathrm{ml})$ of triamcinolone acetonide was injected into the four quadrants (to extend the anti inflammatory effect in the scar tissue) of the esophageal stricture without dilution to avoid diminishing the effect of steroid at intervals of 2 weeks until improvement, but in another study, injection of $2 \mathrm{ml}(40 \mathrm{mg} / \mathrm{ml})$ of triamcinolone acetonide into quadrant 3,4 of the esophageal stricture at intervals of 2 or 3 weeks until full recovery occurred [15]. Such difference in protocols is expected in such relatively new intervention.

Contrary to the current findings, another randomized, double-blind triamcinolone (10$\mathrm{mg} / \mathrm{mL}$ ) and saline, triamcinolone injections did not reduce the dilatation frequency and dysphagia score compared to placebo, but 
increased the diameter of the dilators passed in the following sessions [16].

In this study, in cases with a long stenotic area then dilation, we initially inject steriods in the proximal sections. It opens the stenosis and allows access to the more distal areas of the stenosis. The involvement of active inflammation in endoscopy stringency and the duration of stringency may also support a better response to steroid injection. However, in another study, the authors suggested that patients with long stringencies should first undergo dilatation, followed by injections 2 hours later so that the entire duration of the string can be injected [5].

Several studies have documented successful treatment of refractory esophageal strictures using a combination of balloon dilation and systemic steroid administration, including the benefit of high-dose systemic steroids to avoid strict recurrence [17].

In contrary, other researchers used shortterm oral steroid therapy for 5 days with prednisolone $(2 \mathrm{mg} / \mathrm{kg} /$ day), with successful results obtained, as the stricture formation occurs within the first 3 days of wound healing, Therefore, steroid administration for the first 3-4 days may be sufficient in preventing restenosis, minimizing the collagen content of the tissue and having anti-inflammatory activity [18].

Nonetheless, other studies have taken 3-6 weeks of long-term steroid administration $[17,19]$.

Several research indicated that balloon dilatation with intralesional steroid injection was successful in patients with esophageal rigidity, several subsequent studies in adults and pediatric patients confirmed this result [19].

Bhutani et al. used a mini-probe endoscopic ultrasound to direct the injection into the thickest part of the stricture for better results. In their research, after only partially responding (for 12 wk) to steroid injection without ultrasound guidance, one patient with a stricture of $4 \mathrm{~cm}$ responded well to steroid injection under ultrasound mini-probe guidance (for 6 months) [20].

\section{CONCLUSIONS}

The findings of the current study support the use of intralesional triamcinolone in corrosive esoghageal stricture as an adjuvant treatment to dilatation therapy, as it improved the outcome in the studied cases.

The conclusions of this study were limited by the small sample size and the short follow-up period.

Intralesional steroid injection should be used in corrosive esophageal stricture as an adjuvant treatment to dialatation therapy.

Conflict of interest: Nothing to declare Financial disclosure: Nothing to declare REFERENCES

1. Baskın D, Urgancı N, Abbasoglu L, Alkım C, Yalcin M, Karadag C, et al. standardised protocol for the acute management of corrosive ingestion in children. Pediatri Surg Int. 2004; 20(12):824-828.

2. Salzman M, O'Malley RN. Updates on the evaluation and management of caustic exposures. Emerg. Med. Clin. N. Am. 2007; 25(2):459-476.

3. Chinski A, Foltran F, Gregori D, Ballali S, Passali D, Bellussi L. Foreign bodies in the oesophagus: the experience of the Buenos Aires Paediatric ORL Clinic. Int. J of pediatri. 2010:1-6.

4. Zheng J, Chang Z, Liu Z, Lu Z, Zhao J, Ma Y, et al. Retrievable Z-stents for the treatment of refractory corrosive esophageal strictures in children. Eur J Pediatr Surg. 2015; 3(2):160-164.

5. Kochhar R, Ray JD, Sriram PV, Kumar S , Singh K. Intralesional steroids augment the effects of endoscopic dilation in corrosive esophageal strictures. Gastrointest Endosc 1999; 49:509-513.

6. Kochman ML, McClave SA, Boyce HW. The refractory and the recurrent esophageal stricture: a definition. Gastrointest Endosc., 2005;62(3):474475 .

7. Takahashi H, Arimura Y, Okahara S, Kodaira J, Hokari K, Tsukagoshi H, et al. Hosokawa M. A randomized controlled trial of endoscopic steroid injection for prophylaxis of esophageal stenoses after extensive endoscopic submucosal dissection. BMC gastroenterology. 2015;15(1):1.

8. Ahn Y, Coomarasamy C, Ogra R. Efficacy of intralesional triamcinolone injections for benign refractory oesophageal strictures at Counties Manukau Health, New Zealand. NZ Med J. 2015;128:44-50. 
9. Kochhar R, Makharia GK. Usefulness of intralesional triamcinolone in treatment of benign esophageal strictures. Gastrointest Endosc., 2002;56(6):829-834.

10. Altintas E, Kacar S, Tunc B, Sezgin O, Parlak E, Altiparmak E, et al. Intralesional steroid injection in benign esophageal strictures resistant to bougie dilation. SJGH. 2004;19(12):1388-1391.

11. Gandhi RP, Cooper A, Barlow BA. Successful management of esophageal strictures without resection or replacement. J Pediatr Surg. 1989;24(8):745-750.

12. Zein NN, Greseth JM, Perrault J. Endoscopic intralesional steroid injections in the management of refractory esophageal strictures. Gastrointest Endosc., 1995; 41(6):596-598.

13. Orive-Calzada A, Bernal-Martinez A, NavajasLaboa M, Torres-Burgos S, Aguirresarobe M, Lorenzo-Morote M, et al. Efficacy of intralesional corticosteroid injection in endoscopic treatment of esophageal strictures. Surg Laparosc Endosc Percutan Tech., 2012; 22(6):518-522.

14. Narang S, Kansal S, Bherwani S, Shetty S, Vyas KY. Effect of Intralesional Triamcinolone Injection in Patients of Esophageal Stricture Post Acid Ingestion. J Den Med Sci., 2017; 16(3): 91-94.

15. Bicakci U, Tander B, Deveci G, Rizalar R, Ariturk E, Bernay F. Minimally invasive management of children with caustic ingestion: less pain for patients. Pediatri Surg Int. 2010;26(3):251255.

16. Camargo MA, Lopes LR, Grangeia TD, Andreollo NA, Brandalise NA. Use of corticosteroids after esophageal dilations on patients with corrosive stenosis: prospective, randomized and double-blind study. Rev Assoc Med Bras. 2003;49(3):286-392.

17. Hishiki T, Kouchi K, Saito T, Terui K, Sato Y, Mitsunaga T, et al. Successful treatment of severe refractory anastomotic stricture in an infant after esophageal atresia repair by endoscopic balloon dilation combined with systemic administration of dexamethasone. Pediatri Surg Int. 2009; 25(6):531533.

18. Morikawa N, Honna T, Kuroda T, Watanabe K, Tanaka H, Takayasu H, F et al. High dose intravenous methylprednisolone resolves esophageal stricture resistant to balloon dilatation with intralesional injection of dexamethasone. Pediatri Surg Int. 2008; 24(10):1161-1164.

19. Kobayashi S, Kanai N, Ohki T, Takagi R, Yamaguchi $\mathbf{N}$, Isomoto $\mathbf{H}$, et al. Prevention of esophageal strictures after endoscopic submucosal dissection. World J Gastroenterol. 2014; 20(41):15098.

20. Bhutani MS, Usman N, Shenoy V, Qarqash A, Singh A, Barde CJ, et al. Endoscopic ultrasound miniprobe-guided steroid injection for treatment of refractory esophageal strictures. Endoscopy. 1997; 29(08):757-759.

\section{Cite This Article}

Ismail, N., Mansour, S., Hussien, H. The Efficacy Of Intralesional Steroid Injection in The Treatment Of Corrosive Esophageal Strictures in Children. Zagazig University Medical Journal, 2021; (48-57): -. doi: 10.21608/zumj.2020.19016.1613 